\title{
Two p16 (CDKN2A) germline mutations in 30 Israeli melanoma families
}

\author{
Emanuel Yakobson ${ }^{1}$, Pnina Shemesh ${ }^{4}$, Esther Azizi ${ }^{4}$, Eyal Winkler ${ }^{5}$, Norman Lassam ${ }^{9}$, \\ David Hogg ${ }^{9}$, Sharon Brookes ${ }^{10}$, Gordon Peters ${ }^{10}$, Michal Lotem ${ }^{7}$, Abraham Zlotogorski ${ }^{7}$, \\ Marina Landau ${ }^{3}$, Mark Safro ${ }^{8}$, Raphael Shafir ${ }^{2}$, Eitan Friedman ${ }^{6}$ and Hava Peretz ${ }^{1}$ \\ ${ }^{1}$ Laboratory of Clinical Biochemistry, Departments of ${ }^{2}$ Plastic Surgery and ${ }^{3}$ Dermatology, Tel Aviv University \\ Sourasky Medical Center, Tel Aviv; D epartments of ${ }^{4}$ Dermatology, ${ }^{5}$ Plastic Surgery and ${ }^{6}$ The Susanne Levy Geatner \\ Oncogenetics Unit, Sheba Medical Center, Tel Hashomer; ${ }^{7}$ Department of Dermatology, Hadassah Medical Center, \\ Hebrew University, Jerusalem; ${ }^{8}$ Department of Structural Biology, Weizmann Institute of Science, Rehovot, Israel; \\ ${ }^{9}$ Department of Medicine, University of Toronto, Canada; ${ }^{10}$ Imperial Cancer Research Fund, London, UK
}

Germline mutations in the p16 (CDKN2A) tumour suppressor gene have been linked to inherited predisposition to malignant melanoma (MM). Variable frequencies of p16 germline mutations were reported in different collections of melanoma families but it can be as high as $\mathbf{5 0 \%}$. Here we describe the results of p16 mutation screening in $\mathbf{3 0}$ melanoma kindreds in Israel. The entire coding region of the p16 gene, including exons 1, 2 and 3, flanking exon/intron junctions, and a portion of the 3' untranslated (UTR) region of the gene were examined by single-stranded conformation polymorphism (SSCP) analysis and direct sequencing. Two p16 germline mutations were identified: G101W, which has been previously observed in a number of melanoma kindreds, and G122V, a novel missense mutation. Thus, the frequency of mutations identified in this collection of Israeli families was $7 \%$. Functional analysis indicated that the novel G122V variant retained some capacity to interact with cyclin dependent kinases (CDKs) in vitro, yet it was significantly impaired in its ability to cause a $\mathrm{Gl}$ cell cycle arrest in human diploid fibroblasts. This partial loss of function is consistent with the predicted impact of G122V substitution on the 3-dimensional structure of the p16 protein. European Journal of Human Genetics (2000) 8, 590-596.

Keywords: p16; CDKN2A; germline mutations; Israeli Jewish melanoma families

\section{Introduction}

The $\mathrm{p} 16^{\mathrm{INK} 4 \mathrm{a}}$-cyclin D1-CDK4-retinoblastoma protein ( $\mathrm{pRb}$ ) pathway is recognised as a major target of genetic alterations in diverse human cancers (see reviews ${ }^{1,2}$ ). One of the most frequently altered genes is the p16 $6^{\text {INK4a }} / C D K N 2 A$ tumor suppressor which sustains inactivating lesions in a wide variety of sporadic tumours, notably $T$ cell acute lymphoblastic leukemia (T-ALL), gliomas and bladder cancer, and is perturbed in $50-75 \%$ of established human tumour cell lines. ${ }^{2,3}$ Germline mutations in p16 occur in families that show inherited predisposition to malignant melanoma. ${ }^{2,4-6}$

Correspondence: Hava Peretz, Laboratory of Clinical Biochemistry, Tel Aviv University, Sourasky Medical Center, Tel Aviv, Israel. Tel: +972 3 6973406; E-mail: hperetz@tasmc.health.gov.il

Received 7 January 2000; revised 3 March 2000; accepted 4 April 2000 and in some instances to pancreatic and head and neck cancers. $^{7,8}$

About 230 melanoma families worldwide have been screened for germline alterations in p16 and 36 different mutations have been identified thus far. ${ }^{2}$ The estimated frequency of p16 mutations in familial melanoma varies from 8 to $50 \% .^{9-11}$ Some of this variability could reflect the different ways in which familial inheritance of melanoma is inferred. For example, in two studies a positive correlation was noted between the frequency of p16 mutation and the number of $\mathrm{MM}$ affected individuals within a given melanoma family. ${ }^{10,11}$ Ethnic background may also be significant in determining the frequency of germline mutations, as was shown for several genes predisposing to cancer. For example, specific mutations in the BRCA1 and BRCA2 tumor suppressor genes causing breast and ovarian cancer have been 
found at elevated frequencies among Ashkenazi and nonAshkenazi Jews. ${ }^{12,13}$ Similarly, a hypermutable tract in the APC tumor suppressor gene occurs at a frequency of $28 \%$ in Ashkenazi Jewish individuals with family or personal histories of colorectal cancer. ${ }^{14}$ With these precedents in mind, we have examined the prevalence and nature of p16 germline mutations in 30 Israeli melanoma families of both Ashkenazi and non-Ashkenazi Jewish origin. A preliminary account of these studies has been published elsewhere. ${ }^{15}$

\section{Materials and methods \\ Melanoma families}

Melanoma families were recruited from patient population consecutively followed at the Dermatology and Plastic Surgery Departments of three major Israeli Medical Centers: Sheba, Tel Hashomer, Sourasky, Tel Aviv and Hadassah Jerusalem. Ethnic origin was defined according to paternal and maternal grandparents. Ashkenazi Jews were classified as those who originate in Eastern and Central European countries. Non-Ashkenazi Jews were either of Sephardic (Spanish,
North African, Balkan etc) or of Oriental (Iraqi, Iranian, Yemenite, Egyptian etc) origin. Kindreds examined in this study contained two, three, or four individuals with clinically and histologically confirmed MM. Two individuals with multiple primary melanomas were also examined. The presence of other cancers in the families studied was established through medical records and in part reported by patients themselves. DNA samples from only one MM affected member were available for mutation analysis in 25 families. In five families two or three MM affected individuals were examined for p16 germline alterations. All the participants enrolled in this study received a brief explanation of the aims of the study and signed an informed consent form. The study was approved by the internal review board/Helsinki committee of the participating Medical Centers.

\section{Mutation detection}

Genomic DNA was extracted from peripheral blood. PCRSSCP analysis of the entire p16 coding region (including exon 1 , exon 2 fragments $2 \mathrm{~A}, 2 \mathrm{~B}, 2 \mathrm{C}$ and exon 3 ) and an

Table 1 Summary of clinical data and p16 sequence alterations in melanoma probands

\begin{tabular}{|c|c|c|c|c|c|}
\hline $\begin{array}{l}\text { DNA } \\
\text { sample }\end{array}$ & $\begin{array}{l}\text { Proband (age at } \\
\text { diagnosis) }\end{array}$ & Ethnic origin & $\begin{array}{l}\text { M M-affected relatives } \\
\text { (age at diagnosis) }\end{array}$ & Other cancers in the family & Sequence alterations ${ }^{\mathrm{b}}$ \\
\hline AZ 01 & Female (22) & Sephardic & Father (40), aunt (28) & & $442 \mathrm{G}>A$, Ala148Thr, 500C>G \\
\hline M3 & Male $(35,57)^{a}$ & Oriental & & & \\
\hline M6 & Female (42) & Ashkenazi & Mother & Colon (mother), breast (aunt) & \\
\hline M15 & Female (46) & Ashkenazi & Father & & \\
\hline M29 & Male (50) & Ashkenazi & Cousin & & \\
\hline M33 & Male (44) & Ashkenazi & Mother, uncle & & \\
\hline M45 & Male (22) & Ashkenazi & Mother & & $500 C>G$ \\
\hline M46 & Male (44) & Ashkenazi & Brother (46) & Brain (brother) & \\
\hline M48 & Male (80) & Ashkenazi & Sister (70) & & \\
\hline M50 & Male (37) & Ashkenazi & Aunt, cousin (34) & & \\
\hline M51 & Male (40) & Ashkenazi & Father, brother (39) & & \\
\hline M55 & Female (39) & Sephardic & Twin sister (39) & Lymphoma (cousin) & \\
\hline M57 & Female (18) & Ashkenazi & Mother & Pancreatic (grandmother) & $500 C>G$ \\
\hline M59 & Female (45) & Ashkenazi & $\begin{array}{l}\text { Mother, cousin, } \\
\text { nephew }\end{array}$ & $\begin{array}{l}\text { Colon (mother), } \\
\text { Pancreatic (sister), Breast (sister) }\end{array}$ & \\
\hline M77 & Male (43) & Sephardic & Mother & & $442 \mathrm{G}>$ A, Ala48Thr, $500 \mathrm{C}>\mathrm{G}$ \\
\hline $5 \mathrm{M}$ & Male (54) & Ashkenazi & Sister & Schwannoma (proband) & 442 G>A, Alal48Thr, 500 C>G \\
\hline $21 \mathrm{M}$ & Female (55) & Italian & Mother & & $301 G>T$, Gly101Trp \\
\hline $22 \mathrm{M}$ & Female $(31,32)^{a}$ & $\begin{array}{l}\text { Sephardic \& } \\
\text { Oriental }\end{array}$ & Aunt (56) & & \\
\hline $23 M$ & Male (37) & Ashkenazi & Daughter (27) & & 442 G>A, Ala148Thr \\
\hline $24 M$ & Female (46) & Ashkenazi & Daughter & & \\
\hline $25 M$ & Male (54) & Greek & Sister (41) & & 365G >T, Gly122Val \\
\hline $27 M$ & Male (67) & Ashkenazi & Daughter (27) & Glioblastoma (brother) & \\
\hline $35 M$ & Female (80) & Ashkenazi & Daughter (19) & Breast (daughter) & \\
\hline $37 M$ & Female (35) & Ashkenazi & Mother & & \\
\hline $40 M$ & Female (44) & Ashkenazi & Father & & \\
\hline $47 M$ & Male (23) & Ashkenazi & Mother & Glioma (mother) & \\
\hline $48 \mathrm{M}$ & Male (60) & Ashkenazi & Brother (46) & $\begin{array}{l}\text { Multiple basal cell } \\
\text { carcinoma (brother) }\end{array}$ & \\
\hline $49 M$ & Male $(43,57)^{\mathrm{a}}$ & Ashkenazi & & & \\
\hline $51 \mathrm{M}$ & Female (22) & Ashkenazi & Aunt, uncle & & \\
\hline $52 \mathrm{M}$ & Female (48) & Oriental & Brother & & \\
\hline
\end{tabular}

atwo primaries; ${ }^{\mathrm{b}}$ mutations are shown in bold. 
untranslated $3^{\prime}$ portion of the gene, direct sequencing of aberrant bands and restriction enzyme analysis were carried out as described by us earlier. ${ }^{15}$ In addition, DNA from a subset of families of this collection was examined by direct sequencing of PCR products as described. ${ }^{16}$ The $-34 \mathrm{G}>\mathrm{T}$ substitution in the $5^{\prime}$ UTR of the p16 gene was assayed as previously described ${ }^{16}$ except for changing the annealing temperature to $63 \mathrm{C}$.

\section{Molecular modelling}

The effect of G122V substitution on the three-dimensional structure of 16 protein molecule was examined by designing a model for $\mathrm{p} 16$ from $\mathrm{C} \alpha$ coordinates of $\mathrm{p} 18$ (kindly provided by Ronen Marmorstein). The model was drawn by using the RIBBON 2.5 program $^{17}$ and by omitting the fifth ankyrin repeat, which is not present in the p16 protein. ${ }^{18}$

\section{Functional characterisation of the variant forms of p16}

The functional evaluation of the G122V variant form was performed as described in detail elsewhere. ${ }^{19}$ The G122V mutation was introduced into the wild-type p16 cDNA sequence using synthetic oligonucleotides containing the required base substitution and the QuickChange mutagenesis procedure according to the manufacturer's protocols (Stratagene, San Diego, CA, USA). Protein-protein interaction assays were performed using components synthesi sed in vitro by coupled transcription and translation of plasmid DNAs. ${ }^{20}$ The CDKs were labelled by incorporation of ${ }^{35} \mathrm{~S}$-methionine. The protein complexes were immunoprecipitated with a polyclonal antiserum against the carboxy terminal region of p16, fractionated by SDS-PAGE in a $12 \%$ polyacrylamide gel and labelled components were visualised by autoradiography.

TIG-3 human diploid fibroblasts expressing the cell surface receptor for mouse ecotropic retrovirus (TIG-ER cells) were generated as previously described ${ }^{21}$ and infected with recombinant retroviruses encoding wild-type and variant p16 sequences. $^{20}$ After $24 \mathrm{~h}$, the medium was replaced and selection in medium containing $2.5 \mu \mathrm{g} / \mathrm{ml}$ puromycin, was initiated on day 2 post-infection and continued for a further 4 days. Equivalent numbers of puromycin resistant cells $\left(5 \times 10^{3}\right)$ were plated in 24-well plates and, at various times thereafter, cell numbers were compared by staining with crystal violet. ${ }^{19}$ The relative numbers of viable cells were determined by measurements of absorbance at $590 \mathrm{~nm}$. Values were normal ised to that obtained at day zero and each time point was assayed in triplicate.
ASHKENAZI

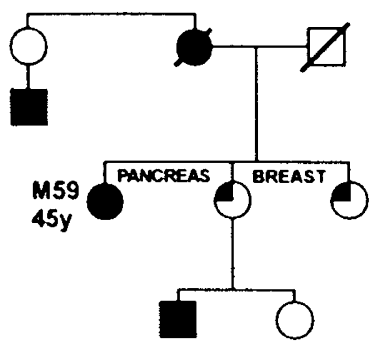

ITALIAN

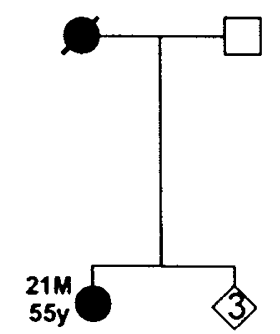

Gly 101 Trp
ASHKENAZI

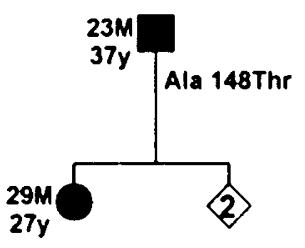

GREEK

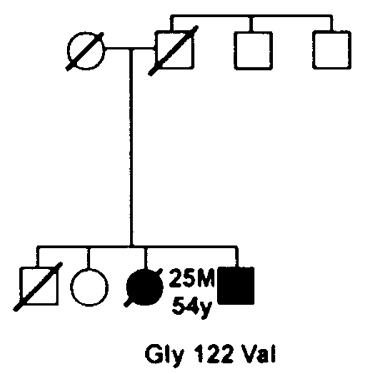

ASHKENAZI

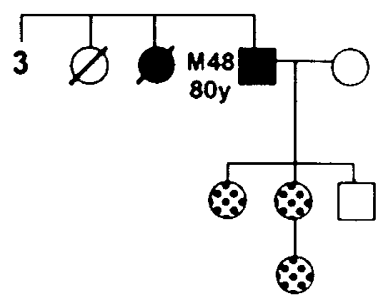

ASHKENAZI

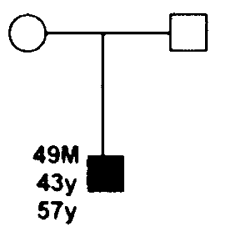

Figure 1 Six representative pedigrees of Israeli melanoma families. Filled squares and circles indicate males and females with MM. Upper quarter filled symbols indicate individuals with other cancers. Dotted symbols indicate presence of atypical mole syndrome. Ethnic origin, age at diagnosis (y) and sequence alterations are indicated. 


\section{Results}

\section{Melanoma-prone families}

Thirty families were evaluated in the present study. One family contained four MM patients, five families, three patients and 24 families, two patients. In addition two patients with two primary melanomas were examined. In 27 families patients were first degree relatives, and in three families MM patients were second degree relatives. In nine families affected individuals were within the same generation, in 20 families within two generations, and one family M M spans three generations. Ages at diagnosis ranged from 18 to 80 years (mean $=41.4,1 S D=14.6$ ). From the data published by the Israel Cancer Registry on the newly diagnosed melanoma cases among Jews in 1988 we have estimated the average age at diagnosis as 54.4 years. Atypical Mole Syndrome (AMS) was assessed according to published criteria $^{22}$ in 15 families. AMS score equal to 3 , conferring increased risk for melanoma was observed in three families. Other malignancies observed in related family members included: pancreatic cancer in two families, breast cancer in three families, brain tumours in four families, colon cancer in

\section{A. SSCP analysis}

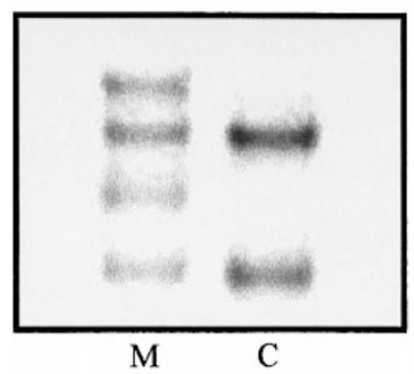

two families and other cancers in three families. Twenty-four families were of Ashkenazi-Jewish origin and the remaining eight families were of non-Ashkenazi origin. The relevant clinical details on the Israeli melanoma prone families are presented in Table1 and pedigrees of six representative families are depicted in Figure 1.

\section{p16 nucleotide sequence alterations}

DNA from $37 \mathrm{MM}$ patients representing 30 families and two individuals with multiple primary melanomas was examined by SSCP analysis followed by nucleotide sequence analysis. Sequence variations were identified in nine families (Table 1 ). Direct sequencing of all exons and exon-intron boundaries of the p16 gene revealed no additional sequence variations in a subset of 15 families.

A novel missense mutation, $365 \mathrm{G}>\mathrm{T}$, coding for Gly122Val amino acid substitution was identified in a Sephardic-Jewish family (25M) originating from Salonika, Greece (Figure1 and Figure2). The proband, a 54-year-old male, was diagnosed having MM and AMS score 2 . His sister

\section{B. Nucleotide sequence}

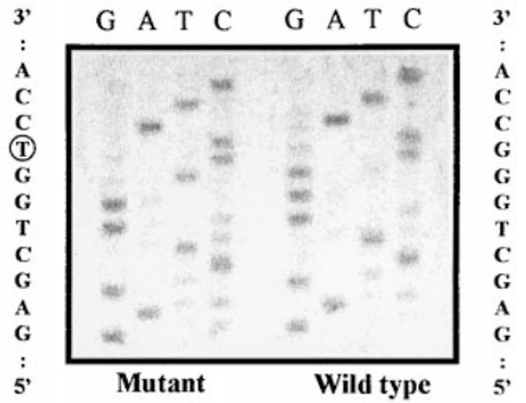

\section{Restriction digest}

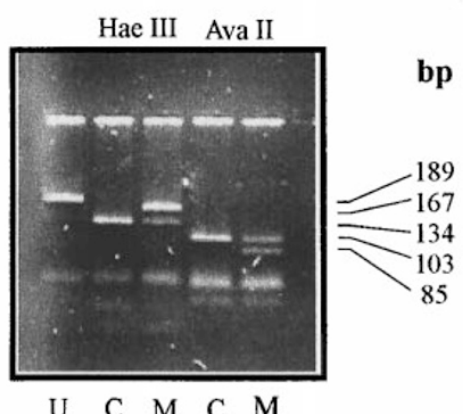

Figure 2 Identification of the 365G >T (Gly122Val) mutation A SSCP pattern of PCR fragment 2C of exon 2. M, individual 25M affected with melanoma (see pedigree in Figure 1); C, control B Nucleotide sequence of aberrant (M) and control (C) SSCP alleles. The $\mathrm{G}$ to $\mathrm{T}$ change is indicated by a circle $\mathbf{C}$ Confirmation of nucleotide sequence alteration by restriction analysis with HaellI $\left(G G^{*} C C\right)$ and Avall (G*GTCC) in control (C) and patient 25M (M) genomic DNA. The 189 bp long, undigested PCR fragment 2C is shown in lane U. Digestion by Hae III results in fragments of 134, 33, and 22 bp for wild type, and fragments of 167 and 22 bp for mutated alleles respectively. Digestion by Ava II results in fragments of 103,51 and 35 bp for wild type allele and fragments of 85 , 51,35 and $18 \mathrm{bp}$ for mutated allele. 
died from MM at the age of 45 having been diagnosed at the age of 41 .

A second missense mutation, $301 \mathrm{G}>\mathrm{T}$, encoding for Gly101Trp amino acid substitution was identified in patient 21M of Italian Jewish origin (Figure 1). The proband was a 55-year-old female (AMS score0), whose mother died from MM. The Gly101Trp mutation is a known melanoma causing mutation, which was detected in several families. $^{3,4,7,11,23}$

The Ala148Thr polymorphism was identified in five out of the 32 probands (15.6\%, Table1). The frequency of this polymorphism in a control population sample was $8 \%$ (8/100). In two families, $A Z 01^{15}$ and 23M (Figure1) this polymorphism did not co-segregate with the disease. The 3'UTR $500 \mathrm{C}>\mathrm{G}$ polymorphism was identified in five instances (Table 1). The recently identified $-34 \mathrm{G}>\mathrm{T}$ mutation in the $5^{\prime}$ UTR of the p16 gene ${ }^{16}$ was not detected in all the patients analysed.

\section{The effect of the Gly122Val mutation on the structure and function of the p16 protein}

The p16 protein belongs to a group of ankyrin motif containing proteins. ${ }^{24}$ Four an kyrin repeats comprise al most $80 \%$ of the p16 molecule length. The availability of the three dimensional structure of the related human p18 protein allowed us to examine the possible effect of the Gly122Val mutation on the p16 molecule. ${ }^{18}$ Glycine at position 122 facilitates the formation of a sharp turn between the $\alpha 7$ and $\alpha 8$ antiparallel helices in the fourth ankyrin repeat of the 16 protein. ${ }^{18}$ Its replacement by valine, which exposes a hydrophobic sidechain towards the solvent, will apparently lead to the destabilisation of the ankyrin molecule (Figure3).

The functional evaluation of the Gly 122 Val variant protein was carried out by testing its ability to bind to CDK4 and CDK6, and its ability to cause a G1 cell cycle arrest in a human diploid fibroblast proliferation assay. Whilst binding of the variant protein to CDK6 was similar to that of the wild type protein, binding to CDK4 was significantly reduced (Figure4A). The mutant protein was also less effective than the wild type protein in its ability to inhibit fibroblast proliferation (Figure4B).

\section{Discussion}

Two p16 germline mutations were detected in $30 \mathrm{Israeli}$ Jewish melanoma-prone families. A novel G122V missense mutation was identified in a 54-year-old patient whose sister died of melanoma at the age of 45 (family $25 \mathrm{M}$ in Figure1). Several lines of evidence suggest that the G122V alteration is not a polymorphism but rather a disease-causing mutation. This mutation was not detected in any other MM patient studied, and was not detected among 30 unrelated sporadic melanoma patients or in 56 control healthy Jewish individuals. Glycine 122 is within the consensus ankyrin motif sequence. It is fully conserved in the INK4 proteins p15, p16,

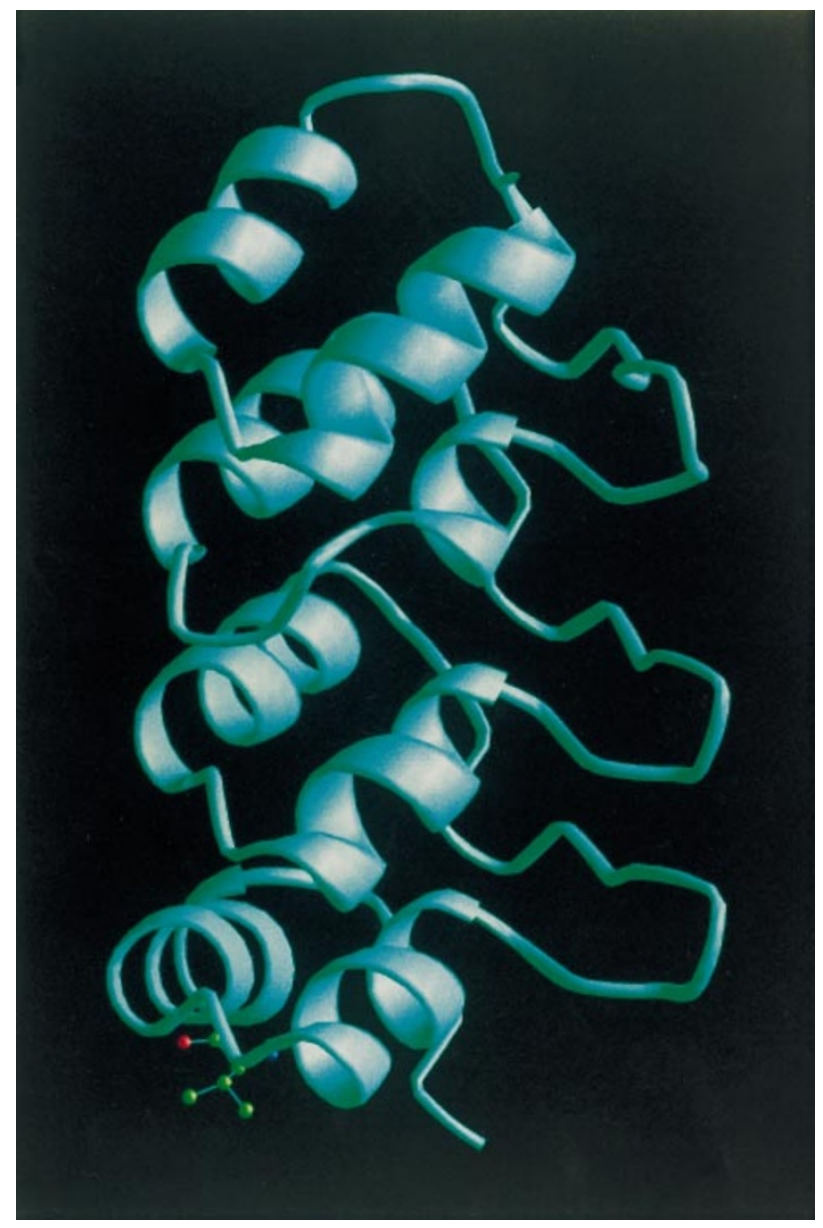

Figure 3 The effect of Gly122Val amino acid substitution on the 3-dimensional structure of p16 protein molecule. A ribbon model of $\mathrm{p} 16$ was derived from $\mathrm{C} \alpha$ coordinates of $\mathrm{p} 18$ omitting the fifth ankyrin repeat, which is not present in p16. The 122 Val residue is illustrated by ball-and-sticks. It can be seen that the Val residue is surface located at the turn between the 7th and 8th $\alpha$-helices. This location and solvent accessibility of the hydrophobic side chain of valine apparently destabilises the ankryin motif.

p18 and $\mathrm{p}^{1} 9^{18}$ and is located at the turn between two antiparallel $\alpha$-helices. The G122V substitution apparently causes destabilisation of the p16 protein because of the relatively bulky side chain of valine as compared with that of glycine (Figure3). Moreover, in functional tests, the G122V mutation impairs the binding of the p16 protein to CDK4 and its ability to cause a $\mathrm{G} 1$ cell cyclearrest in human diploid fibroblasts. A similar glycine to serine substitution (G122S) was reported as a somatic mutation in a biliary tract tumor. ${ }^{25}$

The G101W mutation has been previously described in a number of melanoma kindreds, ${ }^{3,4,7,11,23}$ including seven unrelated families in Italy. ${ }^{23}$ Since the family $21 \mathrm{M}$, harbouring this mutation is of Italian origin, further studies comparing p16 gene linked haplotypes in the Italian and Israeli MM 
A

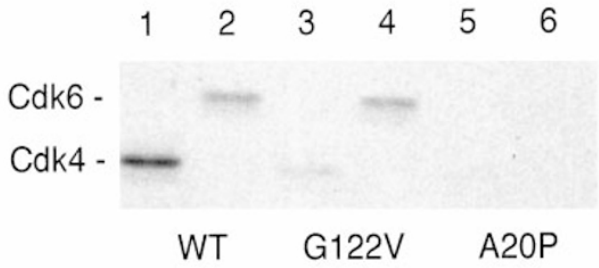

B

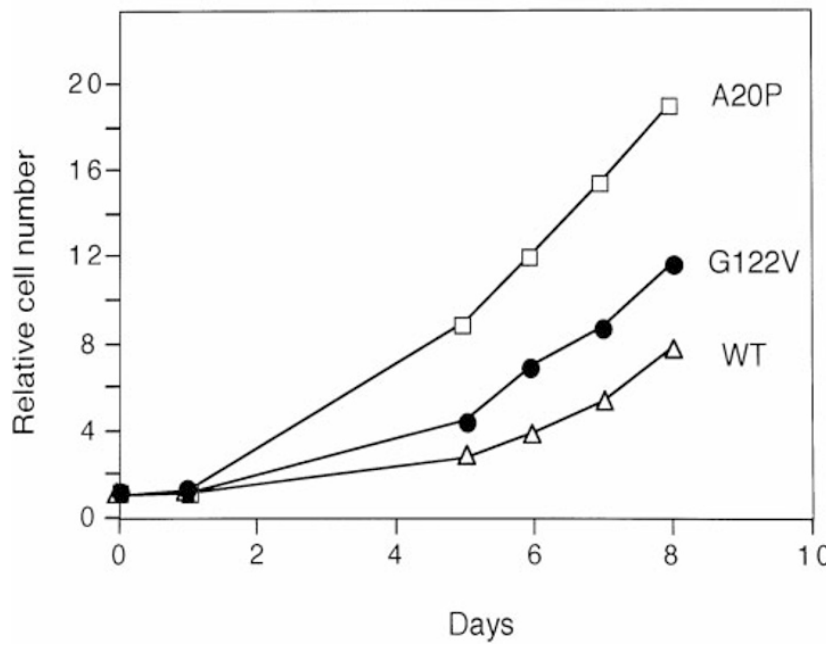

Figure 4 Functional evaluation of p16 variants $\mathbf{A}$ The ability of p16 variants to bind to CDK4 (lanes 1,3 and 5) and CDK6 (lanes 2, 4 and 6) was tested by mixing unlabeled p16 with ${ }^{35} \mathrm{~S}$-labelled CDKs, produced by in vitro translation in reticulocyte lysates. The mixtures were immunoprecipitated with antiserum against p16 and the co-precipitated CDKs were analysed by SDS-PAGE and visualised by autoradiography. WT refers to wild-type p16 and A20P is a known loss of function mutant (19) B Inhibition of proliferation of TIG-3 human diploid fibroblasts infected with recombinant retroviruses encoding wild-type and variant p16 sequences. Cell proliferation assays were performed as described in Materials and methods.

affected individuals may clarify whether there is a common origin (founder effect) of this mutation.

Familial predisposition to melanoma is often but not always associated with the Atypical Mole Syndrome (AMS). ${ }^{22,26,27}$ In our study, both the G122V and the G101W mutation carriers did not exhibit significant AMS scores (AMS2 and AMS0, respectively).

The frequency of p16 germline mutations identified in Israeli melanoma families appears to be low (2/30, 7\%). In similar collections of Swedish, UK and French melanoma families, the frequency of p16 gene mutations ranged from 8 to $50 \% .^{9-11}$ The low frequency of detected mutations in the present study is apparently not a result of missed point mutations or small gene aberrations since the results of full DNA sequencing in 15 patients was concordant with the results of SSCP analysis. We cannot exclude, however, that some of the tested individuals represent sporadic melanoma cases especially in the families where only one individual was available for testing.

In previous reports ${ }^{10,11}$ the majority of mutations were detected in families with three or more cases of melanoma. In our series, which included six families with three or more melanoma cases, p16 germline mutations were identified only in families with two melanoma cases. The majority of the families (23/30) in this collection were of Ashkenazi Jewish origin. In contrast with the high frequency of BRCA 1 and BRCA2, founder mutations causing breast and ovarian cancer in Ashkenazi Jews ${ }^{28}$ no such mutations have been found yet in the p16 gene. In other populations, founder mutations in the p16 gene were reported on several occasions. ${ }^{16,23,29-32}$

Examination of a greater number of melanoma families, extension of analysis to non-coding regions of the $\mathrm{p} 16$ gene and screening for large rearrangements involving the p16 gene, will further clarify the role of p16 mutations in familial melanoma in Jews. The possibility of presence of germline mutations in another gene, CDK4, which have been reported in a few melanoma pedigrees $^{11,33}$ should be also investigated.

\section{Acknowledgements}

We wish to thank Ronen Marmorstein for providing 3D coordinates of p18 protein and to Graeme Walker for DNA samples with known p16 mutations. The excellent technical assistance of Sali Usher is greatly appreciated. This study was partially supported by grants from the Israel Cancer Association and the Dr David Cytrinic and Chaya Cytrinic Memorial Fund for Medical Research, Tel Aviv University, Sackler School of Medicine.

\section{References}

1 Bartek J, Bartkova J, Lukas J: The retinoblastoma protein pathway in cell cycle control and cancer. Exp Cell Res 1997; 237: 1-6.

2 Ruas M, Peters G: The p16 $1 \mathrm{IK}^{\mathrm{NK}} / \mathrm{CDKN} 2 \mathrm{~A}$ tumor suppressor and its relatives. Biochim Biophys Acta 1998; 1378: 115-177.

$3 \mathrm{Kamb}$ A, Gruis NA, Weaver-Feldhaus J et al: A cell cycle regulator potentially involved in genesis of many tumor types. Science 1994; 264: 436-440.

4 Hussussian CJ, Struewing JP, Goldstein AM et al: Germline p16 mutations in familial melanoma. Nat Genet 1994; 8: 15-21.

$5 \mathrm{Kamb}$ A, Shattuck-Eidens D, Eeles R et al: Analysis of the p16 gene (CDKN2) as a candidate for the chromosome9p melanoma susceptibility locus. Nat Genet 1994; 8: 22-26.

6 Foulkes WD, Flanders TY, Pollock PM, Hayward NK: The CDKN2A (p16) gene and human cancer. Mol Med 1997; 3: 5-20.

7 Whelan AJ, Bartsch D, Goodfellow PJ: A familial syndrome of pancreatic cancer and melanoma with a mutation in the CDKN2 tumor suppressor gene. N Engl J Med 1995; 333: 975-977.

8 Yarbrough WG, Aprelikova O, Pei H, Olshan AF, Liu ET: Familial tumor syndrome associated with a germline nonfunctional p16 INK4a allele. J Natl Cancer Inst 1996; 88: 1489-1491.

9 Platz A, Hansson J, Mansson-BrahmeE et al: Screening of germline mutations in the CDKN2A and CDKN2B genes in Swedish families with hereditary cutaneous melanoma. J Natl Cancer Inst 1997; 89: 697-702. 
10 Harland M, Meloni R, Gruis N et al: Germline mutations of the CDNK2 gene in UK melanoma families. Hum Mol Genet 1997; 6: 2061-2067.

11 Soufir N, Avril M-F, Chompret A et al: Prevalence of p16 and CDK4 germline mutations in 48 melanoma-prone families in France. Hum Mol Genet 1998; 7: 209-216.

12 Struewing JP, Abeliovich D, Peretz $T$ et al: The carrier frequency of the BRCA1 185delAG mutation is approximately 1 percent in Ashkenazi Jewish individuals. Nat Genet 1995; 11: 198-200.

13 Bar-Sade RB, Kruglikova A, Modan B et al: The 185delAG BRCA1 mutation originated before the dispersion of Jews in the Diaspora and is not limited to Ashkenazim. Hum Mol Genet 1998; 7: 801-805.

14 Laken SJ, Petersen GM, Gruber SB et al: Familial colorectal cancer in Ashkenazim due to a hypermutable tract in APC. Nat Genet 1997; 17: 79-83.

15 Yakobson EA, Zlotogorski A, Shafir R et al: Screening for tumour suppressor p16(CDKN2A) germline mutations in Israeli melanoma families. Clin Chem Lab Med 1998; 36: 645-648.

16 Liu L, Dilworth D, Gao L et al: Mutation of the CDK2NA 5' UTR creates an aberrant initiation codon and predisposes to melanoma. Nat Genet 1999; 21: 128-132.

17 Carson M: Ribbons. Methods Enzymol 1997; 277: 493-505.

18 Venkataramani R, Swaminathan K, Marmorstein R: Crystal structure of the CDK4/6 inhibitory protein $\mathrm{p} 18^{\mathrm{INK} 4 \mathrm{C}}$ provides insights into ankyrin-like repeat structure/function and tumor-derived p16 ${ }^{\text {INK4 }}$ mutations. Nat Struct Biol 1998; 5: 74-81.

19 Ruas M, Brookes S, McDonald NQ, Peters G: Functional evaluation of tumour-specific variants of $\mathrm{p} 16^{\mathrm{INK} 4 \mathrm{a}} / \mathrm{CDKN} 2 \mathrm{~A}$ : correlation with protein structure information. Oncogene 1999; 18: 5423-5434.

20 Parry D, Peters G: Temperature-sensitive mutations of $p 16^{\mathrm{CDKN2}}$ associated with familial melanoma. Mol Cell Biol 1996; 16: 3844-3852.

21 McConnell BB, Starborg M, Brookes S, Peters G: Inhibitors of cyclin-dependent kinases induce features of replicative senescence in early passage human diploid fibroblasts. Curr Biol 1998; 8: $351-354$
22 Newton Bishop JA, Bataille V, Pinney E, Bishop DT: Familial studies in melanoma: identification of the atypical mole syndrome (AMS) phenotype. Melanoma Res 1994; 4: 199-206

23 Ciotti P, Strigini P, Bianchi-Scarra G: Familial melanoma and pancreatic cancer. New Engl J Med 1996; 334: 469-470.

24 Bork P: Hundreds of ankyrin-like repeats in functionally diverse proteins: mobile modules that cross phyla horizontally? Proteins 1993; 17: 363-374.

25 Yoshida S, Todoroki T, Ichikawa $\mathrm{Y}$ et al: Mutations of $\mathrm{p} 16^{\mathrm{INK} 4} /$ CDKN2 and $\mathrm{p} 15^{\text {INK4B/MTS2 }}$ genes in biliary tract cancers. Cancer Res 1995; 55: 2756-2760.

26 Greene MH: The genetics of hereditary melanoma and nevi. 1998 update. Cancer 1999; 86(11 Suppl): 2464-2477.

27 Newton Bishop JA, Wachsmuth RC, Harland M et al: Genotype/ phenotype and penetrance studies in melanoma families with germline CDKN2A mutations. J Invest Dermatol 2000; 114: 28-33.

28 Warner E, Foulkes W, Goodwin P et al: Prevalence and penetrance of BRCA1 and BRCA2 gene mutations in unselected Ashkenazi Jewish women with breast cancer. J Natl Cancer Inst 1999; 91: 1241-1247.

29 Gruis NA, van der Velden PA, Sandkuijl LA, Prins DE et al: Homozygotes for CDKN2 (p16) germline mutation in Dutch familial melanoma kindreds. Nat Genet 1995; 10: 351-353.

30 Borg A, Johansson U, Johansson $O$ et al: Novel germline mutation in familial malignant melanoma in Southern Sweden. Cancer Res 1996; 56: 2497-2500.

31 Pollock PM, Spurr N, Bishop T et al: Haplotype analysis of two recurrent CDKN2A mutations in 10 melanoma families: evidence for common founders and independent mutations. Hum Mutat 1998; 11: 424-431.

32 Ghiorzo $\mathrm{P}$, Ciotti $\mathrm{P}, \mathrm{M}$ antelli $\mathrm{M}$ et al: Characterization of ligurian melanoma families and risk of occurrence of other neoplasia. Int J Cancer 1999; 83: 441-448.

33 Zuo L, Weger J, Yang Q et al: Germline mutations in the p16 ${ }^{\text {INK4a }}$ binding domain of CDK4 in familial melanoma. Nat Genet 1996; 12: 97-99. 